\title{
Post-conflict contexts and humanitarian organizations: the changing relationship with states
}

\author{
Andrew J. Cunninghame
}

\begin{abstract}
The operational environments for humanitarian international non-governmental organizations (INGOs) are conflict zones and situations of natural and man-made disasters. To INGOs, these are defined as "humanitarian crises." Post-conflict situations present far less clear-cut choices for humanitarian INGOs. This article queries whether humanitarian crises continue into postconflict periods. Clearly, the question is not for humanitarian INGOs to answer on their own, as host governments have their own perspectives on the nature of crises, a perspective which generates political sensitivities for the relationship constructed between states and humanitarian INGOs. The nature of this relationship changes as a conflict transitions from active war to the early days of peace. This article researches the changing relationship between the humanitarian INGO Médecins Sans Frontières (Holland) (MSF-H) and the Government of Sri Lanka (GoSL) in the period 2009-2012. Many variables contributed to the decision-making on continued presence in post-conflict Sri Lanka by MSF-H against the security policies of the government of Sri Lanka. Priorities such as protection, witnessing, and medical aid were in tension with governmental policies related to the emerging peace and the changing context. A "war-immediate post war-post conflict" transitional framework based on Koselleck's definition of crisis is proposed to help organizations understand the war-to-peace transition and construct their relationships with states. This crisis analysis is set against the background of the literature on linking relief, rehabilitation, and development and Walter Benjamin's conception of peace. Throughout, the focus is on the concept of transition.
\end{abstract}

Keywords: Humanitarian crisis, Post conflict, Médecins Sans Frontières, INGO, Sri Lanka

\section{Introduction}

A post-conflict context can be conceptualized as a transitional period bounded by past war and future peace, a period which introduces a number of new challenges. Whether a war was civil or international in scope, concluded through a peace agreement or by a military victory, for states, a war's conclusion is a time to consolidate political gains. For international actors, these transitional periods also necessitate adaptation. Some actors must take on new roles, such as the United Nations shifting from peace mediation to peacekeeping. New actors may also enter onto the scene after the fighting ends, such as development agencies. Humanitarian organizations have a particularly difficult time adapting to transitional periods. The challenges such organizations

Correspondence: Cunninghamandrew2@gmail.com

Conflict, Security and Development Research Group, Department of War Studies, King's College London, 16A Stoke Newington Common, London N16 7ES, UK face when confronted with a post-conflict context is the focus of this article.

One way of conceptualizing this transitional period is through the concept of linking relief, rehabilitation, and development (LRRD). The LRRD concept links "shortterm relief measures with longer term development programmes in order to create synergies and provide a more sustainable response to crisis situations" (Ramet, 2012: 4). The concept is enshrined in the Principles of Good Humanitarian Donorship, where organizations should "provide humanitarian assistance in ways that are supportive of recovery and long-term development, striving to ensure support, where appropriate, to the maintenance and return of sustainable livelihoods and transitions from humanitarian relief to recovery and development activities." ${ }^{1}$ LRRD can be looked at from various perspectives-as a continuum or, as is the case with the donor European Community Humanitarian Aid Office (ECHO), as a "contiguum" (Ramet, 2012: 4). In a changing 
context, such as a post-conflict situation, it may not be possible to work through the stages in order-such a situation rather calls for complementarity of approaches and implies flexibility. Complementarity, however, is only feasible in the context of a common assessment of risks and desired outcomes (Pantuliano and O'Callaghan, 2006: 29).

A lack of clarity persists in transitional periods. Far from linking relief and development interventions, rehabilitation activities often maintain "emergency-type responses which focus on material supply issues at the cost of addressing underlying structural problems" (Macrae, 1995: 1). But then again, "even once the hazard (conflict) has passed, conflictaffected communities will remain extremely vulnerable" (ibid: 8). In the end, it is often difficult to decide whether aid activities should be concerned with relief, rehabilitation, or development (Seaman, 1994). The development versus humanitarianism "has become a monotonous critique, constantly rehashing this basic dilemma and reproducing its lyrical dispositions" (Duffield, 2007: 50). It may also be asked whether the distinctions reflect the context or are simply informed by the mandates and world views of organizations (Davies, 1994), for humanitarian NGOs have indeed extended into development, relief, and peacebuilding programming. There are two views on the appropriateness of this phenomenon-NGOs should "stick to their classical role as providers of relief and protection" or expand their development and peacebuilding strategies (Goodhand, 2006: 2). This article takes the former perspective and focuses on the role of humanitarian organizations in relief and protection and how they respond to contextual pressures to take the latter view.

Taking a traditionalist view, the raison d'etre for humanitarian international non-governmental organizations (INGOs) is to respond to "humanitarian crises." A humanitarian INGO commonly defines a crisis as a context of armed conflict, man-made emergency, or natural disaster. The effects of these crises may include displacement, war wounded, malnutrition, or disease outbreaks. A typical view focuses humanitarian action on the imperative to alleviate suffering, save lives, and restore dignity to those living amid crisis.

Humanitarian agencies clearly do not make decisions in isolation, as they must work within the parameters set out by states. The relationship between states and humanitarian INGOs is constructed and changes as a context moves from a war into a post-conflict period. The aid-conflict interaction is a two-way street (Goodhand, 2006: 101). An INGO must therefore take into account a government's views and actions when determining whether or not a crisis exists and whether it should continue its work. The relationship between states and humanitarian INGOs is, however, one of chronic tension. States, as sovereign actors, when confronted with international civil society actors that are seen to be independent of political forces, will often attempt to limit their activities and manage the perceived threat they pose to the political order. Humanitarian INGOs are particularly suspect as their mandate compels them to engage with the most politically sensitive of contexts, that of conflict.

The relationship between humanitarian INGOs and states is particularly problematic when negotiated against the politically sensitive background of civil conflict, although "impatience with bureaucratic constraints reflects a naivete about highly political contexts in which NGOs increasingly operate" (Weiss, 1996: 459). States and humanitarian INGOs ground their action in different sets of norms. States make reference to political norms, such as sovereignty, whereas humanitarian INGOs derive their actions from a set of moral norms that justify their right to provide assistance to the suffering other, assistance provided outside the political realm. These sets of norms are in dynamic tension, as "humanitarian norms, more than most kinds of norms, challenge central notions about sovereignty and the organization of international politics in important ways" (Finnemore, 1996: 70). A fundamental tension exists between a political actor that claims sovereign decision-making and a member of civil society that claims both independence from the political order and a right to unhindered access to a state's most sensitive areas and populations. Humanitarian INGOs and states must work hard at "maintaining the idea of a politically, territorially and culturally bounded state on one hand, and independent, neutral, apolitical NGOs on the other" (italics in original) (Amarasuriya and Spencer, 2012: 120). Each actor attempts to retain its identifying features while constructing a relationship which must adapt to changing circumstances. NGOs, however, "control few of the parameters within which they work" (Goodhand, 2006: 125).

This article attempts to place international humanitarian organizations in the post-conflict context, against the background of the LRRD concept, and does so through exploring the changing interactions between such organizations and states. A central question is when is a crisis no longer a crisis? The next section explores ways in which to conceptualize crisis.

\section{Crisis analysis}

If a "violent conflict is less about breakdown than about reordering and transformation" (Goodhand, 2006: 149), then Walter Benjamin's definition of peace may be the best corollary. Benjamin thought of peace as "the historical struggle to sever th[e] nexus between violence and law in political experience," where "this violent restoring and preserving of the legal ends of power and authority contains the insoluble paradox of all justifications of the foundations of legal violence: the contingency of violence itself is exposed as the most, and perhaps only, secure means of founding and justifying law" (Teixeira, 2015: 199-200). In such a reordering of peace, law no 
longer justifies violence in the name of the law. A state of exception is transformed into a more "normal," political, and legal environment. This process, however, is not quick and not simple.

Given these linked views, a possible way of interpreting the concept of crisis is as a "historically immanent transitional phase" (Koselleck, 2006: 372). Emphasis should be given to the transitional aspect. Transitions necessitate decisions, as actors must move from a phase where action has been decided upon to an uncertain period where different actions are demanded. Transitions often bridge conceptually sharper and more coherent phases, though a transitional phase can after a time become the norm against which a subsequent transitional phase is evaluated. For example, war can be thought of as a transitional phase between two eras of peace, but a prolonged conflict may become the norm, as occurred in Sri Lanka where the civil war lasted for 26 years. When such a transition will happen and what the consequences will be, depends on the "diagnosis" made (Koselleck, 2006: 372). When a diagnosis is made, an investigation is conducted into the nature of a problem to identify the treatment indicated. Of especial interest here is the diagnosis, rather than an objective view of the presence of a crisis. Indeed, "a perception among national and international actors that there is an opportunity for peace and recovery" (Macrae, 1995: 4) may be one of the most important landmarks in a post-conflict transition.

What ethic of decision-making is used by humanitarian NGOs in such a situation? One option is a consequentialist ethical framework where "assistance [is] conditional on assumptions regarding future outcomes" (Duffield, 2001: 75). A guiding principle is to do no harm. In humanitarian action, consequences must always be analyzed (Terry, 2002: 216). Humanitarianism is, indeed, about constraints (Terry, 2002: 17). Taken together, organizations must make a proper diagnosis of the situation in order to make the right decisions on which actions to take, based on an analysis of the consequences such decisions may engender.

To ground these reflections in empirical evidence, the next section examines the experience of the international humanitarian organization Médecins Sans Frontières (Holland) (MSF-H) in the "post-conflict" period in Sri Lanka.

\section{Post-conflict Sri Lanka and humanitarian assistance}

This case study examines post-conflict Sri Lanka over the period 2009-2012, specifically investigating the relationship between the Government of Sri Lanka (GoSL) and MSFHolland. The period considered here begins after the end of the war in May 2009-the beginning of the transitional phase between war and peace-and extends to 2012, a type of period not very well defined nor understood by conflictfocused humanitarian agencies. MSF-Holland is an international humanitarian organization on the Dunantist side of the humanitarian spectrum, referring to its grounding in humanitarian principles and humanitarian action, as opposed to multi-mandate organizations which mix relief, rehabilitation, and development programming activities.

A humanitarian organization will diagnose a transitionalcrisis-phase through the lens of the humans affected by the events under consideration and what consequences their actions will have on these people. What are the conditions faced by the affected population? Is it an economic, a political, or a humanitarian crisis? As utilized by MSF-Holland, a diagnostic tool of "red flags" can help determine which type of crisis exists. Four red flags are related to populations, one or more of which indicates serious concerns about the "humanitarian" context, and therefore by extension the existence of a humanitarian crisis: presence of displacement (whether internally displaced persons (IDPs) or refugees), violence against civilians, deliberate discrimination, and targeted exclusion. Added to these are two red flags that relate to the work of humanitarian organizations: constraints and/or restrictions on the distribution and receipt of humanitarian assistance and violence against humanitarian staff and property. As a context moves into a phase of conflict, humanitarian organizations must decide whether or not a humanitarian crisis exists, but as a critical mass of red flags typically exists in a context of war, this analysis is relatively clear-cut. A postconflict period, being a transition between war and peace and therefore a different type of context, again challenges humanitarian organizations to decide whether or not a humanitarian crisis exists. But as will be seen, this analysis is much more challenging than that made in the heart of a conflict. There is, of course, a risk that critiques of aid will lead to indecision of the part of NGOs resulting in populations not receiving assistance (Keen, 2008: 140).

A state uses political and security lenses to determine the nature of a crisis. How does a transitional situation affect national security and the nation's sovereignty? How does it influence the political landscape? In a crisis analysis, war is a specific type of transitional period where a state has determined that a political crisis must be managed through military means-a violent transformation of the socio-political order. There are of course other types of crises, such as natural disasters, but these fall outside the scope of this discussion.

How, though, does a state approach a post-conflict transitional phase? It is highly context-dependent, but in general, a post-conflict period can be considered a period of reconstruction. It is a period, for example, of instituting political or constitutional changes, altering the ethnic distribution within the country, realigning the way power is distributed, or renewing the exploitation of economic resources. Peace comes with ending the use of legal violence in the name of protecting the law. If war is about national survival-an existential crisis-a postconflict period is about creating a new political order. A 
state will attempt to quickly normalize a situation by ending the transitional nature of the context. However, even if from a state's perspective, the domestic situation is no longer in a state of conflict, international actors may still see a "crisis," an analysis that may continue to disrupt the domestic order. Humanitarian actors also sometimes fill this "spoiler" role, such as Chechnya beginning in the mid-2000s, where the presence of humanitarian organizations belied the peace rhetoric by the Moscow political elites.

\section{9-2010: the end of the war, the IDP crisis, and the GoSL security concerns}

Immediately after the end of the war, the GoSL's priority was to control the movement of IDPs and in the process filter out Liberation Tigers of Tamil Eelam (LTTE) supporters from the general population of Tamil displaced. Demobilization is the second stage of the DDRR process, following disarmament. The process "needs to be tailormade to address the characteristics of its socio-political, economic and physical environment. An integrated and targeted approach requires the advance coordination of a diverse group of actors involved in the process" (Knight and Özerdem, 2004: 507). In essence, the aim is to keep militias away from post-conflict environment (Alden et al 2011: 15). Approximately 280,000 people were displaced as a result of the fighting (ICRtoP, no date: 4). Two types of camps were created to house the IDPs-rehabilitation centers for demobilized LTTE soldiers and supporters and welfare centers for the remaining displaced (in effect, closed internment camps) (Weissman, 2011: 24-5). The government in 2009 was under pressure by the international community to treat the displaced fairly and to ensure an expeditious return process (ICG, 2010: 4-6). Basil Rajapaksa, Senior Presidential Advisor, stated that almost all of the displaced would be returned home by the end of December 2009 (Swamy, 2010: 170).

The displacement crisis was evaluated and managed as a security matter rather than as a humanitarian crisis in the eyes of the government and military. The need to filter out internal enemies informed the access given to external witnesses and helped determine how the offer of assistance by aid agencies was received. If international humanitarian NGOs represented a threat to the political order, was granting them access an acceptable risk? Conversely, were there gaps in service provision that these organizations could fill, given the intense international pressure on the government to care properly for the IDPs? The immediate post-war period, then, was one of threat analysis and management by the government concerning both the newly occupied former LTTE areas and the existence of the displaced, the latter necessitating the presence of international humanitarian actors. INGOs thus remained a threat and were restricted. To the GoSL, this transitional period was considered a crisis which necessitated decisive action.

For MSF-H in this immediate post-war period, there were clearly medical needs to be met among the displaced population, but there was a lack of access to properly meet those needs. INGOs were not given access to the former LTTE-controlled areas at this time. International organizations were useful to the government in their provision of service but their role of "witnessing"-communicating about what was being seen-was far less desirable. Access to the displaced camps was the key issue for MSF-H (Weissman, 2011: 28).

MSF-H, along with other organizations working in conflict-affected areas of Sri Lanka over the years, had a strained relationship with the GoSL. The last phase of the war had seen the relationship between INGOs and the GoSL deteriorate to a completely dysfunctional level. Access had been severely limited, to the point that in September 2008 INGOs were told to leave the LTTEcontrolled area of the Vanni (Mackintosh, 2010: 387). A confidentiality clause was the price for a renewed Memorandum of Understanding (MoU) between MSF$\mathrm{H}$ and the Ministry of Health. This clause dictated that "no public comments or media release should be made by the partner, without the concurrence of the secretary, Ministry of Health" (Mackintosh, 2010: 388). Visa restrictions were also affecting operational capacity, and INGOs were the target of frequent press attacks. There are various explanations for why any given organization was refused access. For MSF, the most plausible explanation was based on MSF's reputation for speaking out, for "despite the high quality of its medical resources, MSF was barred access to the Sri Lankan battlefield by the government, and relegated to a small ad hoc role treating the wounded civilians who gradually came out from the siege" (Weiss, 2011: 307-8).

An internal MSF-H humanitarian affairs department (HAD) report from the very end of May 2009 gives a good summary of the issues under discussion within the organization immediately after the end of the war (MSFH, 2009a Sri Lanka : Context Analysis and Strategic Direction, 28 May 2009). There was a sense that $\mathrm{MSF}^{2}$ had struggled to find its way since returning in 2006 when the war was again heating up; one MSF operational section, MSF-Spain, had left in December 2008 "feeling that its medical relevance was inadequate to justify a presence." MSF-Holland had failed as well to consolidate its presence from an operational perspective as the government had itself continued to provide medical assistance to both the LTTE and governmentcontrolled areas during the last months of the conflict. Was there a need for a humanitarian organization to remain after the end of the war? In other words, was there 
a humanitarian crisis that necessitated the intervention of a humanitarian organization? The HAD report framed the dilemma as such:

The lack of a clear medical role has served to highlight the real dilemma that MSF faces in Sri Lanka: where we know that there are clear protection concerns and a situation of serious human rights violations, do we have an obligation to remain present? Today, and for the foreseeable future, the Tamil population in the north will be highly vulnerable. If there is no active conflict and the medical needs are not clear, will MSF commit itself to remaining present in the hope that this presence will provide a measure of protection? Even if this means accepting that our medical role will be slim and at times difficult to justify?

The report concluded that the organization did have such a responsibility. Though MSF was not a human rights organization,

we have seen in the past where our presence has managed to at least restrict the violations against civilians that have taken place in Sri Lanka. We cannot assume that human rights and/or protection organizations will be able to negotiate a presence in the camps or among the civilian population.

Moreover, MSF may be considered to have a special responsibility, as we have a status that is somewhat unique among international organizations.

At that stage, the GoSL was allowing a certain amount of international assistance to be given, "but it is clear that they will do their best to prevent this becoming an entrenched role, and that they will do their best to prevent international monitors from having a legitimate reason to remain present." It would be a period in which MSF would only briefly have a medical role, as it was felt that in a matter of weeks or at most months the number of people in need of emergency medical care would be significantly lower. Thus, the organization had to decide on whether it would take on a protection and witnessing role to remain relevant. If not, then "there is really no need for us to seek a medically relevant role for the future or to pull our punches in statements to the world about what is going on. We may indeed be evicted for taking a strong stand on what we are seeing, but if we feel that there is an urgent need to speak out, this may be a risk worth taking."

As can be seen, it was not clear for the organization what exactly its role should be in the immediate post-war period, and concluding what sort of humanitarian needs were present for MSF-H specifically to address was challenging. It was significant that a "protection" objective was explicitly mentioned. The United Nations Office for the Coordination of Humanitarian Affairs (OCHA) defines protection as follows: "Protection broadly encompasses activities aimed at obtaining full respect for the rights of all individuals in accordance with international law-international humanitarian, human rights, and refugee law-regardless of their age, gender, social ethnic, national, religious, or other background." ${ }^{3}$ To MSF-H, protection activities would be implemented through "protection by presence"-providing protection to the civilian population against abuse and neglect through a combination of physical presence and witnessing and speaking out about the situation of a war-affected population. Others, however, have cautioned about its limitations-"its impact on security remains inconclusive and it potentially exposes humanitarian workers to security risks" (Pantuliano and O'Callaghan, 2006: 30).

In such a context, protection activities were difficult to implement when access was being denied; the organization's MoU with the government barred speaking out, and any such advocacy activities could seriously risk eviction from the country. MSF did, in fact, have major difficulties with the Ministry of Health in the last quarter of 2009 over a MSF communication that offended the ministry and nearly ended with the organization being expelled. The choice in June was a difficult one for both MSF sections remaining in the country (MSF-France and MSF-Holland). A decision was in the end made to prioritize the negotiation of access and provision of medical care where possible over public communications and protection activities.

Within MSF, there was considerable debate and frustration in mid- to late 2009 concerning the organization's choice not to speak out publically about what it was witnessing while giving priority to the provision of medical care to the suffering population. The organization's dual mandate of witnessing and medical care often created such dilemmas. What would serve the population better-medical care or a public elaboration of their suffering? The organization explained its decision to itself thusly: "While recognizing, that this population has truly been through horrific experiences, the main concern must be to determine what is MSF's strategy in this situation to create the space to best serve the population" (MSF-H, 2009b Internal Update, 4 June 2009). But, negotiating access was extremely difficult for international agencies, as management of the internally displaced camps was almost completely in the hands of the military and access to the conflict-affected areas was barred to INGOs. Events moved quickly and organizations such as MSF were continually on their back feet reacting to developments and struggling to find operational relevance. MSF remained seriously concerned about the health status of the displaced population in the displaced camps and communicated these concerns 
directly to the government, requesting that the government establish procedures that would facilitate the deliverance of humanitarian aid, particularly regarding the issuance of visas and other required documents to allow experienced international staff to bolster local capacity and provide specialized training and support (Memo from MSF to the GoSL, 20 August 2009). Facilitated access, however, was not forthcoming; by 31 December 2009, over half of the displaced had been returned home, and the MSF sections had closed their emergency operations as to a large extent the IDP "crisis" was considered to be over. In any case, the MSF-supported hospital had never been the largest hospital for the displaced, as only around $5-10 \%$ of the total number of patients had been referred there, so in effect, MSF could not in this way be the major provider of medical assistance to the camp population (Weissman, 2011: 32). As had been predicted by many in the organization, medical relevance had been questionable, and access had remained limited as long as the displaced were left in the camps.

By 2010, security concerns remained on the agenda of the Sri Lankan government, particularly regarding the security context of former LTTE areas. The government remained reluctant to provide international organizations access to the former LTTE areas, which were still to be cleared and filtered. A majority, but not all, of the displaced had been allowed to return to their homes, but their re-integration was still considered primarily a national security issue. Though the IDP crisis had lessened in intensity, there remained heavy international concern about the resettlement process, as the government's resettlement and reconstruction plans were unclear and the "strong military influence over policies, tight military control over the population and restrictions on local and international NGOs" were worrying (ICG, 2010: 1). Understandably, the government had a different view, feeling that the situation was quickly normalizing, it was cooperating with the international community, and it was fulfilling its duties as a responsible government.

In 2010, the justification for continued MSF-H presence in Sri Lanka was discussed internally. The rationale for presence was considered to be the following: "As the conventional war has been won by the GoSL on May 18th 2009, MSF is essentially now responding to the aftermath of the fighting" (MSF-H, 2010b Sri Lanka Country Policy 2010). Despite the Ministry of Health providing basic healthcare inside the welfare centers, gaps in service delivery remained. It was also thought that the authorities were not being as forthcoming as it was wished, concerning the range of medical needs. Crucially, given that the WHO and local NGOs were "embedded with the government," MSF-H felt that there was a need for an impartial organization to remain present. MSF's justification for staying related also to a residual protection role, albeit focusing mainly on medical issues; MSF should

play a role as watchdog to insure good medical practice to these patients [the IDPs in camps]. In the coming months, MSF will have to continuously challenge the authorities to make sure that the IDPs will have proper health access in resettled area. There will be key challenge to insure that wounded and disable patient won't be dump[ed] in the Vanni or in camps without proper care.

These medical needs were directly related to the war and they would not last indefinitely, so at this point thought was given to when the organization would leave and under what conditions. Each MSF-H mission had a set of "exit criteria" - the criteria the organization would use to judge when it was time to close a mission. These exit criteria related directly to the red flags discussed above. For the Sri Lanka mission, the MSF-H Sri Lanka Country Policy (2010b) stated these criteria as:

- Inability to address key humanitarian needs [because of] the obstruction of the government

- Relevance of our action...versus compromise made with the authorities (e.g., external communication)

- The authorities genuinely mobilize and address the major needs and health gaps identified

- Indicators of a new insurgency or new open armed conflict are not present in the coming 12 months

By late 2010, the organization was explicitly addressing the exit criteria from an operational perspective as opposed to an advocacy or protection role (MSF-H 2010a).

The 2003-2006 protection response in Uganda can be used as a comparison to the Sri Lankan situation. In Uganda, as the sixth phase of the conflict progressed-which saw an increased international interest in the conflict-peace negotiations were begun in June 2006 between the government and the LRA, and a ceasefire was signed on 26 August (Dolan and Hovil 2006: 5). As more humanitarian actors arrived and peace came closer, the consequences for humanitarian organizations of the transition "from an explicitly apolitical stance and towards engagement with the political context-cannot be overestimated" (ibid: 18). An increased protection concern increased the sensitivity of the political situation for the Government of Uganda. The "gift" of scaled-up humanitarian intervention could be considered a "Trojan Horse," in that "it had exactly the effect the central government had for so long been seeking to avoid, namely of attracting international attention to the protection disaster in northern Uganda. Not only has this 
undermined the image of Uganda as a success, but it has also threatened Uganda's fragile sense of sovereignty" (ibid).

Fears, therefore, of INGOs exposing the real situation is certainly not limited to Sri Lanka and neither are the choices faced by INGOs about how to approach such situations. How much do organizations concern themselves with politically sensitive protection activities, and how will the attempt to scale up humanitarian assistance to the most vulnerable populations be perceived by the government?

\section{1-2012: post conflict-post humanitarian?}

By 2011, the government had for the most part secured former LTTE areas. During this process, the international community remained concerned about the methods used and doubted the viability of the government's reconciliation plans. The continued major role played by the military in determining the parameters of access to humanitarian agencies was also a worry to international organizations. Although two thirds of the displaced had been returned home, it was "mostly to areas devoid of the most basic amenities" (ICG 2011: 1). Regardless, from the government's perspective, it was time to transition from attending to immediate post-war security issues to longerterm development programming. To properly make this transition, access to the north had to be provided to international development organizations. International criticism about human rights abuses during the war, though, caused the government continued discomfort.

In the 2011 period, MSF-H witnessed fewer and fewer post-war medical needs and there was almost no discussion of protection issues. Was it time to pack up and leave, as it was now time for other types of organizations to take over? As documented in internal reports from the 2011-2012 period, and gleaned through key informant interviews, the focus at this time shifted to the lack of medical needs. There are few references to difficulties working with the government, only to the lack of needs for MSF-H as a humanitarian medical organization to respond to-the lack of gaps in assistance because of the increase in the number and level of access of other organizations and GoSL capacity. The exit criteria, and associated red flags reviewed above, went a long way in defining whether or not there was a crisis. The key indicators were broadly positive-a lack of conflict, an ability of the government to address many of the needs, and increasing access for other international actors. Therefore, a choice was finally made based on the positive exit criteria-the ability of the authorities, and other organizations through better access, to provide services, as well as lack of further conflict. To sum up a difficult internal discussion, the stated reason for closing read:

Access restrictions to the Vanni were lifted in 2011 and a number of INGOs and national NGOs have moved personnel and expanded their activities into the Northern Province. Consequently the authorities or other actors are effectively addressing (most of) the major needs and health gaps identified. Concerning mental health, although the needs remain, MSF-OCA is of the opinion, that the solution requires long term structural commitments which the Ministry of Health as well as other long term development agencies are in a better position to provide (Final Report, Sri Lanka Mission, 2006-2012, MSF-Holland, April 2012).

A letter to "Ministry of Health Officials in Colombo and Jaffna," dated 2 January 2012, addressed the closure of the Mental Health programme: Although the needs in mental health in Kilinochchi District are not presently fully addressed, MSF-H is realistically hopeful that the organization could depart, considering:

- The end of the armed conflict

- The lifting of restrictions to access the Vanni by the Ministry of Defence

- The increase of proposed interventions of $\mathrm{MoH}$ as well as the increase of organizations (INGOs and NGOs) expressing their intention to develop projects in the mental health sector in Northern District

- The Joint Plan for Assistance for Northern Province in 2012 (JPA), setting as one of the priorities the development of community based psycho social services

- The extensive public media campaign launched in December 2011, by the Sri Lanka College of Psychiatrists and the Ministry of Health to raise awareness on facts about mental health and to make expert medical care accessible to all those concerned

In the end, the decision to leave was relatively straightforward and based on an exit criteria logic. Once the context had achieved full "post conflict" status, the decision on whether to stay or to go became simpler. On this view, whereas the immediate post-war period had remained a humanitarian crisis, a "post conflict" phase was also a posthumanitarian period.

Compare this logic with Colombia in the mid-2000s, in a decidedly ambiguous context of conflict where there was "a widespread belief that economic interests have overtaken political ones, and that the guerrillas constitute no more than a large-scale criminal enterprise" (Bonwick 2006: 3). The Colombian government was seen as "simultaneously a source of protection and a threat to the civilian population" (italics in original) (ibid: 4), in that military successes had occurred which had increased security for the population, but a hard-line approach to the conflict had also created more violence in parts of the country. Was it war or 
approaching peace? In this situation, humanitarian organizations were faced with the choice between attempting "to increase their leverage, which may be a very long-term process, or to identify where they are able to make a difference in the shorter term and concentrate there" (ibid: 21). Such a decision affects the timeframe upon which humanitarian organizations will plan, particularly concerning protection programming which is highly politically sensitive. In the case of Colombia, "a first lesson is that effective protection work is a long-term endeavour" (ibid).

For MSF-Holland in Sri Lanka, the planning time was meant to be as short as possible, whereas other organizations in a similar context may have chosen to take on a longer-term view, as was the choice for many in Colombia. In facing a transitional phase, organizations had to choose to either focus on the short-term needs that could be addressed, responding to the context as experienced and expecting to exit as soon as the hoped for peace arrived, or settle in for the long term by engaging more fully with the political actors and issues at stake. The mandates and world views of the organizations informed the decisions, as well as the context.

\section{Crisis as transition}

A crisis can be thought of as a transitional phase, and each actor engaged in a transitional phase will make its own diagnosis of the nature of crisis. The case study has shown the validity of this perspective, and the framework as suggested by Koselleck has proven useful. Moving from a phase where action has been decided upon to an uncertain period where different actions are demanded necessitates decisions however painful is their making. Transitions also bridge conceptually sharper and more coherent phases, such as war and peace, or in the case of humanitarian action, frank emergencies and developmental contexts.

In Sri Lanka, the higher-level transition was from war to peace, but this shift must be broken down into segments-the immediate post-war phase which slowly developed into a "post conflict" period. Each phase brought with it its own issues that had to be responded to by the involved actors. An investigation was made by each actor into the nature of the context to identify what action was appropriate in each segment, and as part of this investigation, each segment was analyzed to determine the changing nature of crisis. It was on this basis that decisions were made.

The criteria used by the government related primarily to security considerations. The government's objectives were to manage the domestic security implications of the displaced-to filter out former LTTE cadres, stabilize the war-affected north, and keep international criticism and actors at bay. The initial post-war period was seen as a period when the active military war was over, but the operations against former LTTE cadres remained ongoing. The tensions with international actors persisted and in many ways became more acute. Regardless, the context soon moved into post-conflict mode and international actors were allowed increased access as service delivery agents.

The crisis for MSF-H related to human needs. As has been seen, MSF-H tried to reconcile what were often contradictory aspects of its identity. Its witnessing and advocacy role was often not compatible with its focus on medical needs and negotiating access. A protection analysis was also at odds with a prioritization of assessing and reacting to gaps in medical care to the war-affected population, especially in a context where the organization had stopped itself from speaking out in a pragmatic attempt to ensure continued operational access. The weight given to the various factors changed over time.

In the immediate post-war period, the rationale for presence was more firmly based on protection concerns as the organization's medical role was questionable, partly due to lack of access and partly due to the GoSL attending to the bulk of the medical needs of the displaced. The further away from the end of the war, though, the more decisions were based solely on medical criteria rather than protection concerns. Through better access, it was discovered what needs the government did not have the technical expertise to respond to and thus where the organization could be medically relevant. At the end of the period under consideration, as the context moved into a post-conflict era, MSF-H made its decision to leave based on the lack of relevant medical needs. The immediate post-war period was unquestionably the most problematic for the organization. In a period characterized by lack of access, protection concerns, but questionable medical needs in those areas that were accessible, it became very challenging to conduct an analysis of the crisis and of MSF-H priorities. A combination of denied access and protection concerns prompted renewed effort to remain, even given questionable medical relevance. In this way, the presence of a crisis was decided as much upon the actions of the GoSL as on a strict assessment of medical needs.

These developments and ambiguities are not limited to the Sri Lankan case but are applicable to other postconflict contexts, as was mentioned in the comparisons to Chechnya, Uganda, and Colombia. Many more examples can be elucidated, such as Kosovo, Tajikistan, and Gaza.

How do these findings relate to the concept of linking relief, rehabilitation, and development? Clearly, there was confusion for MSF-H about roles and responsibilities once the war ended but much less so for the GoSL. The government controlled the situation vis-à-vis access for humanitarian actors, although there was international pressure to improve the humanitarian situation of the IDPs. Using ECHO's perspective, Sri Lanka was a case of "contiguum," rather than continuum, at least in the case of the 
humanitarian actor examined. Complementarity was a more useful perspective than a step-by-step approach, where international actors moved methodically from relief into rehabilitation to development. Different actors maintained unique roles, depending on mandate. For a strictly humanitarian organization, however, complementarity is a more difficult concept to implement. MSF-Holland struggled with how much to be involved with other actors and how quickly to hand over to more competent longer-term focused agencies.

The immediate post-war period was neither peace nor war, although the sensitivities of war persisted. Active fighting was over and the drive was towards "normality." This brings the discussion to the second set of underlying concepts, that of reordering, transformation, and the transition into peace. The conflict could be thought of as a reordering of the political and social context of the country. The consequences of this reordering had to be managed by the GoSL at the end of the war and the process of transformation completed. If peace is a situation of legal violence no longer being used to establish the law, then in a humanitarian context peace may be a situation of the law facilitating humanitarian access in an increasingly normalized context.

In the case study examined, this basic pattern can be detected, particularly around the analysis of protection needs and the concerns with security on the part of the GoSL. In the immediate post-war period, the law was yet used to facilitate humanitarian actor, but rather the law was focused on managing threats and controlling actors. Only as the context moved into a truly post-conflict period did the law begin to relax its grip on humanitarian actors. Consequently, during the immediate post-war period, the lack of access fomented protection concerns, whereas these lessened in the later period.

Taken together, the post-conflict period can be seen as a trying time for the state as well as humanitarian actors, as the transition is not clear-cut and is far from being a stepby-step process. Rather, it is a period of ambiguity which necessitates adaptation. Consequences of action, primarily on the vulnerable populations, must always be properly gauged. Essentially black and white frameworks such as LRRD and war and peace are not as helpful as conceptualizations such as complementarity and transformation.

\section{Conclusion}

This is but one example of a war-immediate post war-post-conflict transition. How a crisis is analyzed and responded to by an INGO and a state will be different in any given situation, as has been briefly indicated through comparisons with Colombia and Uganda. Further questions to be researched include a reflection on what general rules of thumb are applicable to every situation. How other organizations differ in their approaches, such as multi-mandate INGOs that concern themselves with both humanitarian and development aid, should also be explored. Much more work needs to be done on the views of the state.

\section{Endnotes}

${ }^{1}$ https://www.ghdinitiative.org/ghd/gns/principlesgood-practice-of-ghd/principles-good-practice-ghd.html

${ }^{2}$ MSF-France, MSF-Spain, and MSF-Holland are three of the five sections of MSF which are responsible for implementing operations (the others being MSFBelgium and MSF-Switzerland). Collectively, these sections and the other 14 MSF offices throughout the world form the MSF movement. Though this article deals specifically with MSF-Holland, the operations of MSFFrance were also pertinent to the narrative. At times, the discussion also encompasses the MSF movement as a whole; this is indicated by the general acronym "MSF."

${ }^{3} \mathrm{OCHA}$ website, http://www.unocha.org/themes/ protection

\section{Abbreviations}

(I)NGO: (International) non-governmental organization; GoSL: Government of Sri Lanka; HAD: Humanitarian Affairs Department; IDPs: Internally displaced persons; LTTE: Liberation Tigers of Tamil Eelam; MoU: Memorandum of Understanding; MSF (-H): Médecins Sans Frontières (-Holland); OCHA: Office for the Coordination of Humanitarian Affairs

\section{Acknowledgements}

The author appreciates the kind assistance of MSF-Holland in granting access to primary source materials related to its activities in Sri Lanka. The assistance of the Conflict, Security and Development Research Group at the Department of War Studies at King's College London should also be acknowledged.

\section{Funding}

Funding was received from the Royal Norwegian Foreign Ministry for the research phase of this study.

\section{Availability of data and materials}

Data is available and stored with the author.

Ethics approval and consent to participate

Not applicable.

\section{Consent for publication}

Not applicable.

\section{Competing interests}

I am currently on the International Board of MSF but was not in that positon when the original research was being conducted (I was still a PhD student at King's College London-War Studies Department).

Received: 13 April 2017 Accepted: 1 September 2017

Published online: 11 September 2017

\footnotetext{
References

Alden C, Thakur M, Arnold M (2011) Militias and the challenges of post-conflict peace: silencing the guns. Zed Books, London

Amarasuriya H, Spencer J (2012) NGOs, the state and 'cultural values': imagining the global in Sri Lanka. In: Howell J (ed) Global matters for nongovernmental public action. Palgrave Macmillan, Basingstoke, pp 115-132

Bonwick, A (2006) Protection in Colombia: a bottom-up approach. HPG Background Paper, ODI.

Davies S (1994) Public institutions, people and famine mitigation. IDS Bull 25(4):46-54
} 
Dolan, C and L Hovil (2006) Humanitarian protection in Uganda: a Trojan horse? HPG Background Paper, ODI.

Duffield M (2001) Global governance and the new wars: the merging of development and security. Zed Books, London

Duffield M (2007) Development, security and unending war: governing the world of peoples. Polity Press, Cambridge

Finnemore M (1996) National interests in international society. Cornell University Press, Ithaca

Goodhand J (2006) Aiding peace? The role of NGOs in armed conflict. Practical Action Publishing, Rugby

ICG (2010) Sri Lanka: a bitter peace. Asia Briefing 99, 11 January 2010

ICG (2011) Reconciliation in Sri Lanka: harder than ever. Asia Report 209, 18 July 2011. ICRtoP (2018) (International Coalition for the Responsibility to Protect) (no date) Crisis in Sri Lanka. http://www.responsibilitytoprotect.org/index.php/crises/ crisis-in-sri-lanka (last accessed 24 July 2017).

Keen D (2008) Complex emergencies. Polity, Cambridge

Knight M, Özerdem A (2004) Guns, camps and cash: disarmament, demobilization and reinsertion of former combatants in transitions from war to peace. J Peace Res 41(4):499-516

Koselleck R (2006) Crisis. Journal of the history of ideas 67(2):357-400

Mackintosh K (2010) Reclaiming protection as a humanitarian goal: fodder for the faint-hearted aid-worker. Int Hum Legal Stud 1:382-396

Macrae, J (1995) Dilemmas of 'post'-conflict transition: lessons from the health sector. Network Paper 12, ODI.

MSF (2009) Memo from MSF to the GoSL, 20 August 2009.

MSF-H (2009a) Sri Lanka: context analysis and strategic direction. Humanitarian Affairs Department, 28 May 2009.

MSF-H (2009b) Internal Update, 4 June 2009

MSF-H (2010a) Short notes, trip Sri Lanka, 9-16 October 2010, MSF-H Operations Manager Report

MSF-H (2010b) Sri Lanka country policy 2010

MSF-H (2012) Letter to Ministry of Health officials in Colombo and Jaffna. Dated 2 January 2012

Pantuliano, S and S O'Callaghan (2006) The 'protection crisis': a review of field-based strategies for humanitarian protection in Darfur. HPG Discussion Paper, ODI.

Ramet, V (2012) Linking relief, rehabilitation and development: towards more effective aid. Policy Briefing, European Parliament.

Seaman J (1994) Relief, rehabilitation and development: are the distinctions useful? IDS Bulletin 25(4):33-36

Swamy MRN (2010) The tiger vanquished: LTTE's story. Sage, New Delhi

Teixeira HM (2015) The state of exception, divine violence, and peace: Walter Benjamin's lesson. In: Koivukoski T, Tabachnick DE (eds) The question of peace in modern political thought. Wilfred Laurier University Press, Waterloo

Terry F (2002) Condemned to repeat? The paradox of humanitarian action. Cornell University Press, London

Weiss G (2011) The cage: the fight for Sri Lanka and the last days of the Tamil Tigers. The Bodley Head, London

Weiss TG (1996) Nongovernmental organizations and internal conflict. In: Brown ME (ed) The international dimensions of internal conflict. MIT Press, Cambridge

Weissman F (2011) Sri Lanka: amid all-out war. In: Magone C, Neuman M. Weissman F (eds) Humanitarian negotiations revealed: the MSF experience. Hurst \& Company, London

\section{Submit your manuscript to a SpringerOpen ${ }^{\circ}$ journal and benefit from:}

- Convenient online submission

- Rigorous peer review

- Open access: articles freely available online

- High visibility within the field

- Retaining the copyright to your article 